\title{
Percolation phenomena in the polymer composites with conducting polymer fillers
}

\author{
${ }^{1}$ Ivan Franko National University of Lviv, Kyryla and Mefodia Str., 6, 79005 Lviv, Ukraine, aksimen@ukr.net \\ ${ }^{2}$ Rivne State Humanitarian University, Plastova Str., 31,33000 Rivne, Ukraine, galmart@ulr.net
}

\begin{abstract}
The electrical properties of polymer nanocomposites based on dielectric polymer matrices of different types and electrically conductive polymer fillers - polyortotoluidine, polyorthoanisidine and polyaniline have been studied.

It is shown that the concentration dependence of the specific conductivity on the content of fillers has a percolation character with a low "percolation threshold", which depends on the nature of the polymer matrix and polyaminoarene and is 1.7-10.0 vol.\%. The calculated critical parameters of electroconductivity are characteristic of the formation of an infinite 3-dimensional cluster of conductivity and indicate a significant influence of the nature of the components and morphology of the material on the charge transfer processes in such systems. filler.

Keywords: electrical properties, percolation phenomena, percolation threshold, polymer matrix, conductive
\end{abstract}

Received 17 November 2021; Accepted 28 December 2021.

\section{Introduction}

The rapid development of modern technologies requires the creation of "intelligent" or "smart" polymer nanomaterials that would provide a wide range of functional properties, ease of processing and environmental stability $[1-10]$.

The use of electrically conductive polymer fillers in the structure of "intelligent" material allows to create highly efficient devices of new generation: flexible sensors [3, 6], biosensors [4, 8], supercapacitors [9], antistatic and anti-radar coatings [10], solar cells [5, 7], organic displays [11], the principle of operation of which is based on the change of electronic properties of conjugated polymers $[1,5,12-14]$.

Electrically conductive conjugated polyaminoarenes based on polyaniline and its derivatives have their own electronic conductivity and act in composites with polymer matrices as conductive fillers [6]. They combine high conductivity and stability [5, 12, 15], are characterized by simplicity of synthesis and relatively low cost. These polymers can be considered as "synthetic nanometals" with a particle diameter of 10-20 nm and unique electronic, optical, electrochemical and catalytic properties, the ability to absorb radioactive rays.

Under the action of electric potential or chemical agents, electrically conductive polymers can be reversibly oxidized or reduced, thus changing the electrical conductivity, the work of electron yield, optical absorption and other properties [5, 15].

It is known that in polymer-polymer systems that form dielectric polymer matrices of different types, conductivity can be manifested even at low content of conductive filler [6, 14]. The study of percolation phenomena in filled polymer systems is an important fundamental task, as the description of the properties of systems in the vicinity of the critical point opens up prospects for the creation of nanomaterials with predicted functional characteristics.

The peculiarity of conductive polymer-polymer composites is that the improvement of electrical and optical properties is achieved at very low concentrations 


\section{O.I. Aksimentyeva, G.V. Martyniuk}

of fillers ( $\leq 5 \%$ vol.) and depends on their degree of dispersion and interfacial interaction filler - matrix [6]. At some critical concentration of electrically conductive filler, the values of which differ significantly for different systems, an abrupt change in properties is observed [6, 14].

At low filler content, the conductivity value $(\sigma)$ is close to the conductivity of the polymer matrix, in which case the conductive particles or aggregates of particles are isolated from each other. Increasing the filler content to the limit content leads to a sharp transition from the nonconductive state to the conductive state (there is a phase transition insulator-conductor) with the corresponding value of conductivity $\left(\sigma_{c}\right)$. In this case, all filler particles are completely delocalized by the volume of the polymer matrix, and the formed composite has the maximum conductivity, and as a result, an infinite cluster of conductivity is formed [16-19], schematically shown in Fig. 1.

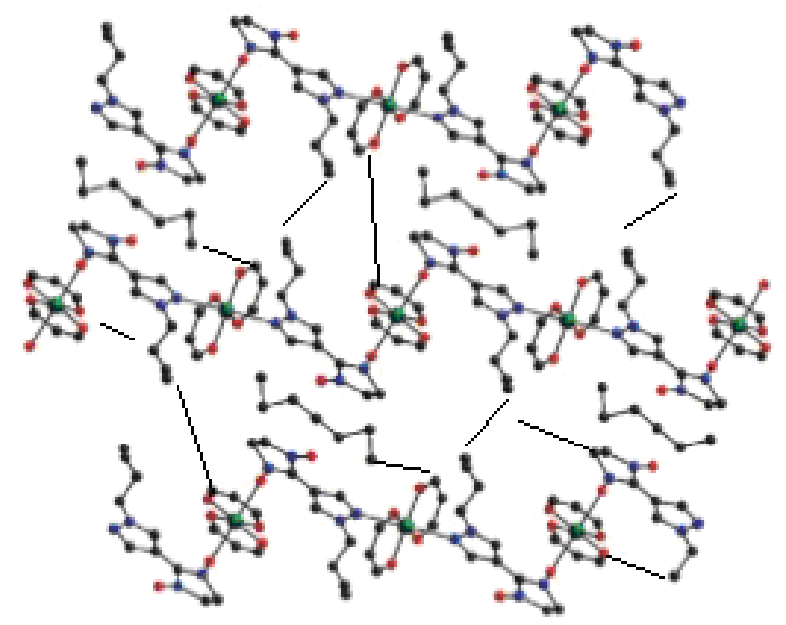

Fig. 1. Schematic representation of an infinite cluster of conductivity.

To scientifically explain the complex dependence of conductivity on the content of electrically conductive filler in composite materials (two-phase systems), a theory was developed, which was formulated for a continuous medium and was called "percolation theory".

This theory determines the value of the critical volume concentration of the conductive phase $\varphi_{C}$, ie the percolation threshold, which allows the insulatorconductor transition in stochastic systems [6, 16-19].

The theory of percolation (flow, impregnation) is a mathematical theory used in chemistry, physics and other fields of science, which describes the emergence of infinite connected structures (clusters) in random (stochastic) mediums consisting of individual elements [20].

This theory makes it possible to describe processes of the most diverse nature, in conditions when the properties of the system change abruptly with a gradual change in one of the parameters (for example, concentration) $[16,17]$. In chemistry, the theory of percolation is used to describe the processes of polymerization, analysis of the mutual distribution of phases in different media. Percolation processes can also lead to self-organization and the formation of nanostructures. The objects that are formed during percolation are fractals. Many publications [16, 17, 20-22] present various models that characterize the dependence of the percolation threshold on the content of the loading filler.

To describe the concentration dependence of the conductivity of filled heterogeneous composite systems, we can use the basic approaches of the theory of effective environment and the symmetric Bruggeman formula: [22]

$$
(1-p) \frac{\left(\sigma_{D C}-\sigma_{m}\right)}{2 \sigma_{D C}+\sigma_{m}}+p \frac{\left(\sigma_{D C}-\sigma_{f}\right)}{2 \sigma_{D C}+\sigma_{f}}=0
$$

$\sigma_{\mathrm{f}}, \sigma_{\mathrm{m}}, \sigma_{\mathrm{DC}}-$ electrical conductivity of the filler, polymer matrix and composite, respectively;

$\mathrm{p}$ - the effective volume content of the filler.

The main equation of percolation theory (Kirkpatrick's model or scaling law) in filled polymer systems, which reflects the dependence of electrical conductivity $(\sigma)$ on the bulk content of the filler $(\varphi)$ after the percolation threshold is the dependence:

$$
\sigma \infty\left(\varphi-\varphi_{i}\right)^{\mathrm{t}}
$$

where $\varphi-$ is the volume fraction of filler, $\varphi_{c}-$ is the percolation threshold, ie the lowest content of filler at which a continuous cluster of conductivity is formed from particles under the condition $\varphi>\varphi_{c} ; \mathrm{t}-$ the critical conductivity index.

To determine the critical parameters, construct a logarithmic dependence $\lg \sigma-\lg \left(\varphi-\varphi_{c}\right)$, the slope of the obtained line gives the value of " $t$ ". For a threedimensional system, the universal constant $(\mathrm{t})$ acquires values of $1.6-2.06$, which mainly depends on the topological dimension of the system and does not depend on the structure of the particles forming the clusters and their interaction. [20-23].

\section{Experimental part}

In this work, the electrical properties of polymerpolymer composites based on dielectric polymer matrices of different types and electrically conductive polymer fillers are investigated. Industrial polymer materials polyvinyl alcohol (PVA), styrene copolymer with maleic anhydride - styromal (StMA), polyacrylic (PAA) and polymethacrylic (PMAA) acids were chosen as polymer matrices. Conjugated polyaminoarenes polyortotoluidine (PoT), polyorthoanisidine (PoA), polyaniline (PANI), used as electrically conductive polymer fillers.

The synthesis of composites was performed by the method of polymerization of aminoarenes directly in a solution (gel) of the polymer matrix in a suitable solvent as described previously [3, 6, 13, 24, 25].

To study the electrical properties the composites in the form of cylinders with dimensions $(\mathrm{d}=1.8 \mathrm{~mm}$, $\mathrm{h}=2.0 \mathrm{~mm}$ ) were made by thermal pressing at a pressure of $150 \mathrm{~atm}$ at appropriate temperatures [26]. The electrical conductivity of the formed composites was measured by the two-probe method at room temperature [6]. Studies of the morphology and microstructure of the 
obtained composites were performed using an optical microscope "Micromed" with a digital camera "Nicon2500 " for film samples formed on the glass surface.

\section{Results and Discussion}

The electrical conductivity of polymer-polymer composites with the same filling depends on the particle size, the homogeneity of the distribution of the conductive filler in the polymer matrix, the nature of the interaction of the components of the conductive and nonconductive phases [15, 24].

The dependence of the logarithm of specific conductivity $(\sigma)$ of the obtained composites based on polymer matrices of different types on the content of polymer filler (PANI, PoT, PoA) is nonlinear and indicates the percolation nature of conductivity in the studied composites (Fig.2, a, b).
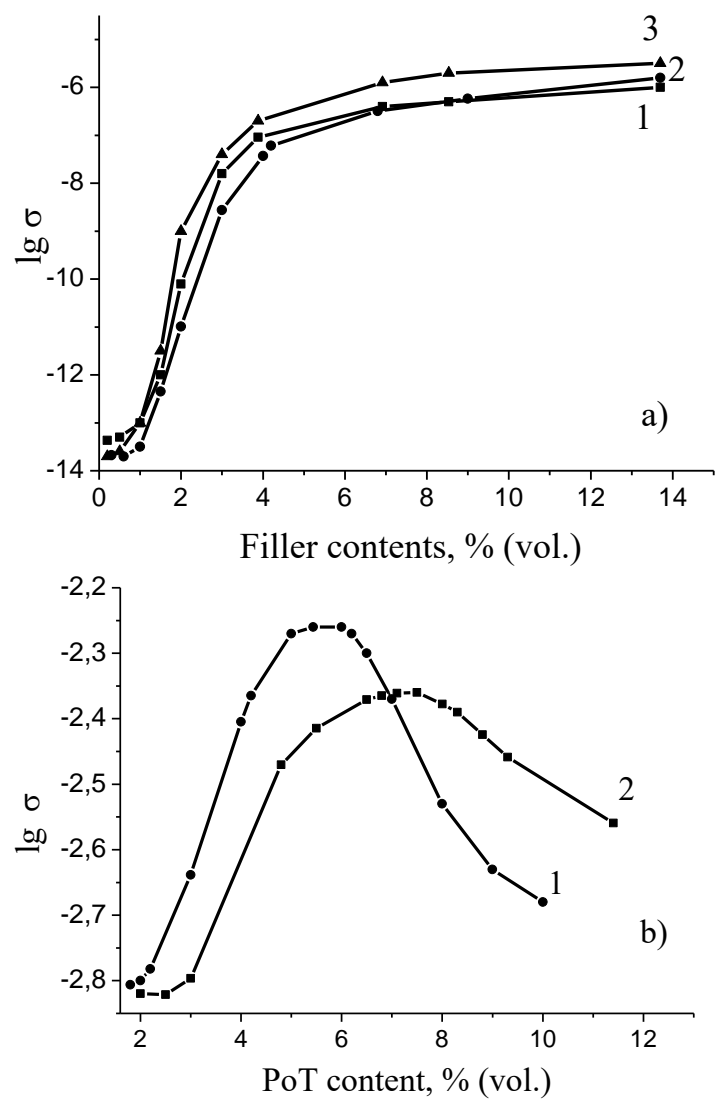

Fig. 2. (a) Dependence of the logarithm of the specific conductivity of PVA-based composites on the content of polymeric filler: 1- PANI; 2 - PoT; 3 - PoA; (b); Dependence of the logarithm of specific conductivity on the content of polymeric filler for composites PAA - PoT (1); PMAA - PoT (2).

The percolation threshold determined from these dependences, at which there is a sharp transition between insulator and conductor, for composites based on PVA is $1.7-2.8 \%$ (vol.), while for the composite PoT - PAA $\varphi_{\mathrm{C}}$ $=2.3 \%$ and $3-4 \%$ for PoT - PMAA. For composites of polyacrylic acids with PoT there is a decrease in specific conductivity at high concentrations of polymeric filler, which may be associated with the formation of a separate phase of PoT, which has a "loosening" effect and contact between individual areas of the composite is broken [6, 24].

Therefore, the filling of the polymeric binder with a conductive highly dispersed filler determines the percolation dependence of the conductivity on the volume content of the filler.

Such low values of the percolation threshold are characteristic of composites with a conductive polymer phase [13]. It can be assumed that the electrically conductive filler forms its own polymer network inside the host polymer and thus a continuous conductive polymer phase is formed, which is evenly distributed throughout the volume of the polymer composite [7, 25, 26]. The obtained photomicrographs of polymer-polymer composites with different content of polymeric filler (before and after the percolation threshold) indicate in favor of this assumption (Fig. 3 a, b).

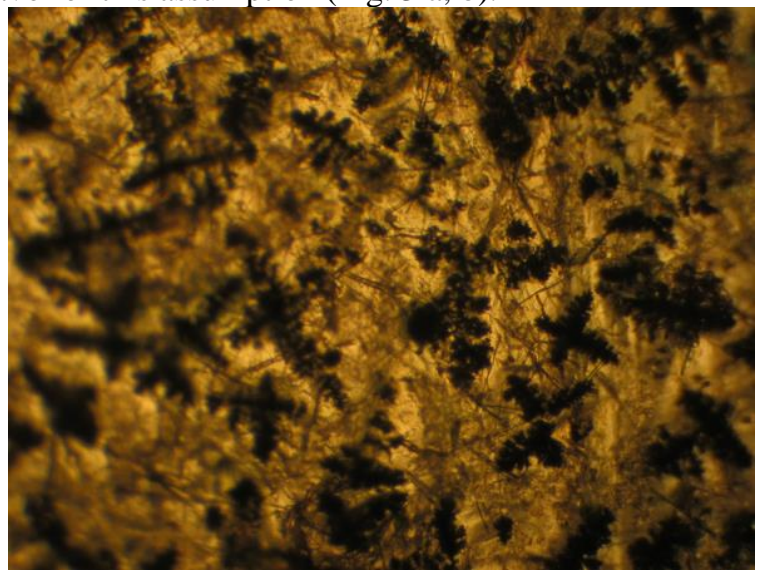

a)

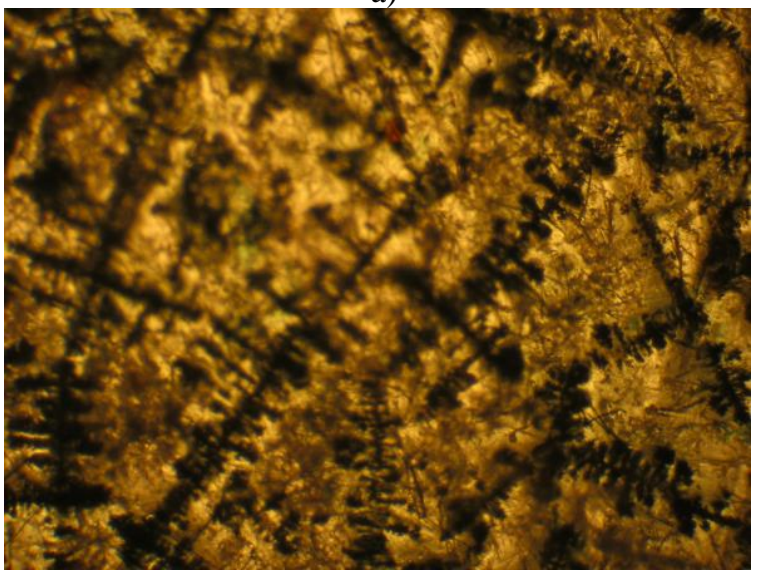

b)

Fig. 3. Micrographs of the surface of polymer composites based on the matrix of PVA and polyaniline as a filler. The content of PANI: (a) $2.0 \%$ vol. (to the percolation threshold); (b) $4.3 \%$ vol. (after the percolation threshold). Magnification 120 times.

It is probable that such a content of conductive filler in the composite ensures proper contact between the particles with the formation of a continuous cluster of conductivity.

When using hydrophobic polymer matrices (PMMA, StMa), the concentration dependence of the specific conductivity of the composite also has a percolation character. For PMAA-PANI composites, an extremely low "percolation threshold" within 2 vol. \% of PANI 


\section{O.I. Aksimentyeva, G.V. Martyniuk}

content was determined [13]. As in the case of other composites $[10,12]$, the concentration dependence of the electrical conductivity of StMA - polyaminoarene composites also has a percolation character [25], but the values of the "threshold" of percolation are slightly higher and are at the level of $\varphi_{\mathrm{C}}=8-10 \%$ vol., and namely: PoT $-10.0 \%$ vol., PANI $-8.4 \%$ vol. and PoA $-8.0 \%$ vol. (Fig. 4).

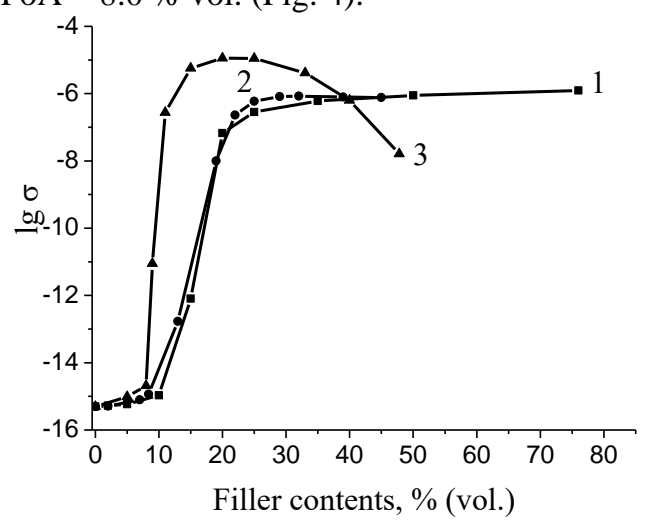

Fig. 4. Dependence of the logarithm of the specific conductivity of composites based on StMA on the filler content for PoT (1), PANI (2), PoA (3).

At this filler concentration, the resistance of the composites decreases by $8-10$ orders of magnitude compared to the resistance of styromal (StMA). As can be seen from the presented photographs (Fig. 5), the electrically conductive polymer in the styromal matrix forms its own percolation grid, and the conduction channels, in contact with each other, provide increased conductivity of composites compared to the StMA matrix.

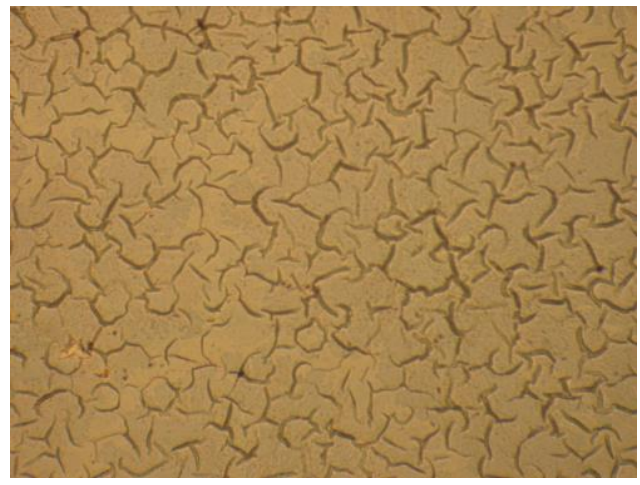

a)

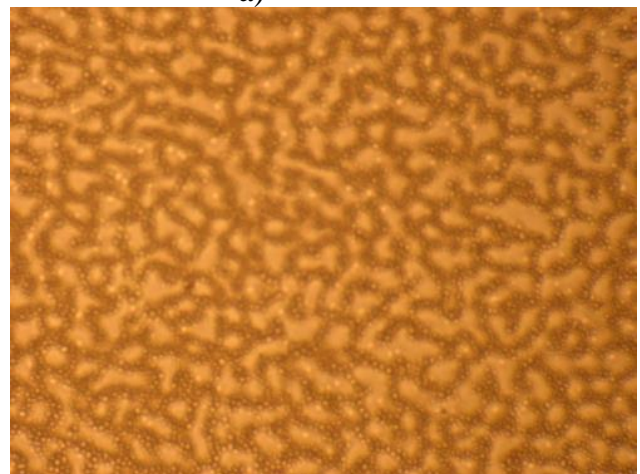

b)

Fig. 5. Photomicrographs of films of composites StMA-PoT with different content of PoT: a $-9.7 \%$ vol.; b $-24.3 \%$ vol [25].
To calculate the critical conductivity parameter after reaching the percolation threshold, the experimental data are presented in logarithmic coordinates according to equation 2. Typical dependences are shown in Fig. 6 (a, $b, c)$, the calculated values of the parameter " $t$ " - in table 1 .

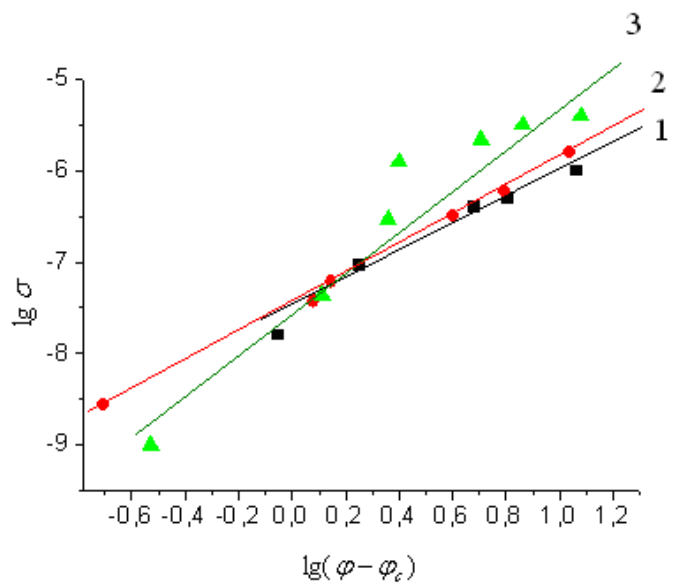

a)

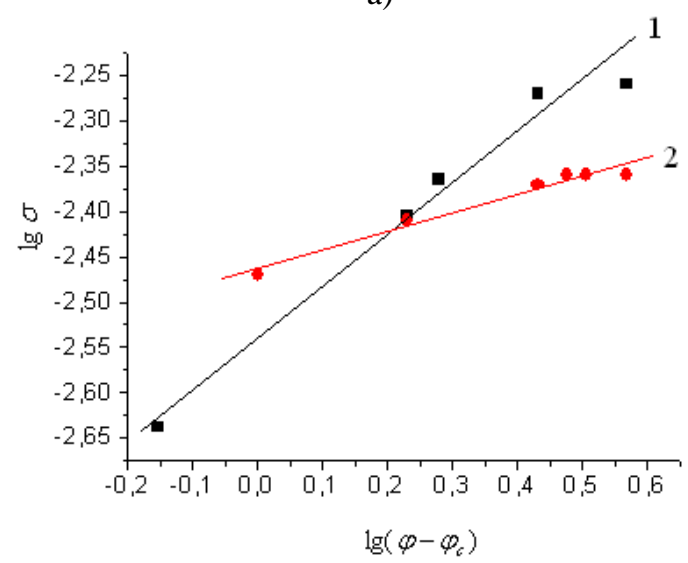

b)

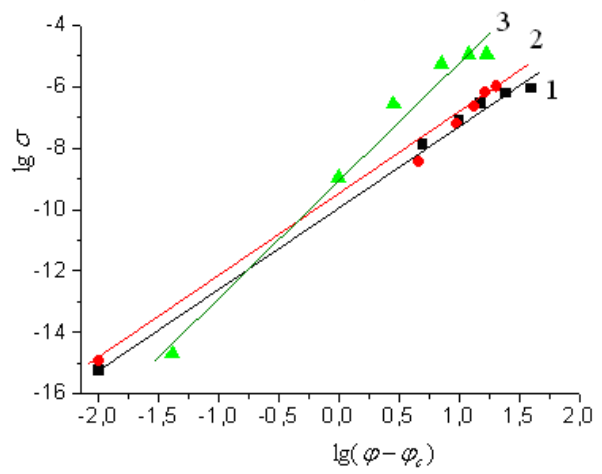

c)

Fig. 6. Logarithmic dependence of specific conductivity on the content of conductive filler after reaching the percolation threshold for composites: (a) PVA-PANI (1), PVA-PoT (2), PVA-PoA (3); (b) PAA-PoT (1), PMAA-PoT (2); (c) StMA-PoT (1), StMA-PANI (2), StMA-PoA (3).

As can be seen from the data shown in table 1, the values of the critical conductivity parameter " $t$ " for the studied composites is from 1.66 to 2.9 and differ depending on the nature of the polymer matrix and the type of polyaminoarene. For composites based on PVA and conjugated polyaminoarenes, the value of 
$\mathrm{t} \approx 1.88-2.25$, which is typical for three-dimensional objects, including those with a porous structure [27] and on average agrees well with the values predicted by the theory of percolation.

Table 1.

Percolation parameters of conductivity of polymer composites with electrically conductive polymer filler.

\begin{tabular}{|c|c|c|c|}
\hline $\begin{array}{c}\text { Polymer } \\
\text { matrix }\end{array}$ & Filler & $\begin{array}{c}\text { Percolation } \\
\text { threshold } \\
\left(\varphi_{\mathrm{c}}\right) \%, \text { vol. }\end{array}$ & $\begin{array}{c}\text { Critical } \\
\text { index “t" }\end{array}$ \\
\hline \multirow{3}{*}{ PVA } & PANI & 2,1 & 1,88 \\
\cline { 2 - 4 } & PoT & 2,8 & 1,54 \\
\cline { 2 - 4 } & PoA & 1,7 & 2,25 \\
\hline PAA & PoT & 2,3 & 1,66 \\
\hline PMAA & PoT & 3,4 & 1,76 \\
\hline \multirow{2}{*}{ StMA } & PoT & 10 & 2,58 \\
\cline { 2 - 4 } & PANI & 8,4 & 2,75 \\
\cline { 2 - 4 } & PoA & 8,0 & 2,9 \\
\hline
\end{tabular}

At the same time, the value of $\mathrm{t} \approx 2$ is observed for many two-phase materials. Significant deviations of this value for composites based on the StMA matrix $(\mathrm{t} \approx 2.58-2.9)$ can be caused by a number of reasons: contact phenomena, in particular, if tunnel contacts are realized between the conductive elements of the material, instead of ohmic [28]; different morphology and different specific surface of the material [29].

The deviation of the critical index " $t$ " from universal values can be explained by the peculiarities of composites formation in "in situ" polymerization conditions, when the electrically conductive filler is formed directly in the dielectric polymer matrix, and by the presence of anisotropic forms of electrically conductive filler.

\section{Conclusions}

It was found that polymer composites based on the studied polymer matrices and conjugated polyaminoarenes are characterized by low values of the percolation threshold, which is typical for composites with an electrically conductive polymer phase.

The conductive filler forms its own polymer network inside the host dielectric polymer matrix, ie a continuous electrically conductive polymer network is formed, which is evenly distributed throughout the volume of the composite, forming a continuous cluster of conductivity

The determined values of percolation parameters (percolation threshold, critical conductivity index) are generally consistent with the main provisions of the theory of percolation for composite systems with dielectric and electrically conductive components. Some deviations of the critical index from the universal values may be due to the nature of the polymer matrix and polyaminoarene, the structure, morphological features and conditions of formation of polymer-polymer composites.

Aksimentyeva O.I. - Professor, Doctor of Chemical Sciences, Chief Researcher and Professor of the Department of Physical and Colloid Chemistry of Ivan Franko National University of Lviv;

Martyniuk G.V. - Candidate of Chemical Sciences, Associate Professor of the Department of Ecology, Geography and Tourism; Rivne State University for the Humanities.

[1] K. Warden, New Intelligent Materials and Designs. Properties and Applications (Technosphere, Moscow, 2006).

[2] M Shahinpoor, H.-J. Schneider, Intelligent Materials. Faculty and Staff Monograph Publications. (The Royal Society of C hemistry, 2008).

[3] O. I. Aksimentyeva, B. R. Tsizh, Yu. Yu. Horbenko, O. I. Konopelnyk, G. V. Martyniuk, M. I. Chokhan', Mol. Cryst. Liq. Cryst. 670(1), 3 (2018), https://doi.org/10.1080/15421406.2018.1542057.

[4] K. Feron, R. Lim, C. Sherwood, A. Keynes, A. Brichta, P. Paul, C. Dastoor, J Mol. Sci. 19(8), 2382 (2018). https://doi.org/10.3390/ijms19082382.

[5] A.J. Heeger, Synth. Metals. 123, 23 (2002).

[6] O. I. Aksimentyeva, O. I. Konopelnyk, G. V. Martyniuk, Computational and Experimental Analysis of Functional Materials. Chapter 9. (Apple Academic Press, Toronto, 2017).

[7] K. M. Ziadan, H. F. Hussein, K. I. Ajeel, Energy Procedia 18, 157 (2012), https://doi.org/10.1016/j.egypro.2012.05.027.

[8] A. Khan, M. Jawaid, A. A. P. Khan, A M. Asiri, Electrically Conductive Polymers and Polymer Composites: (From Synthesis to Biomedical Applications Wiley-VCH, 2018).

[9] P. Naskar, A. Maiti, P. Chakraborty, D. Kundu, B. Biswas, A. Banerjee, J. Mater. Chem. A 4, 1970 (2021). https://doi.org/10.1039/D0TA09655E.

[10] F.X. Qin, H.X. Peng, N. Pankratov, M.H. Phan, L. V. Panina, M. Ipatov, V. Zhukova, A. Zhukov, Journal of Applied Physics 108, 044510 (2010), https://doi.org/10.1063/1.3471816.

[11] O. Aksimenteeva, O. Konopelnyk, I. Olenych, D. Polevoy, Y. Gorbenko, A. Mykhalets, VI Ukrainian Congress of Electrochemistry (Lviv, June 4-7, 2018), p.112.

[12] A. G. Mac Diarmid. "Synthetic Metals": A Novel Role for Organic Polymers (Nobel Lecture), Angew. Chem. Int. Ed., 125, 11 (2001).

[13] O.I. Aksimentyeva, O.I. Konopelnik, G.V. Martyniuk, V.V. Yurkiv, V.A. Shapovalov, Molec. Cryst. Liq. Cryst. 468, 309 (2007). 


\section{O.I. Aksimentyeva, G.V. Martyniuk}

[14] O. Aksimentyeva, O. Konopelnyk, G. Martyniuk et al., Rev. Adv. Mater. Sci. 23, 30 (2010).

[15] [O. I. Aksimentyeva, Electrochemical synthesis methods and conductivity of conjugated polymers (Svit, Lviv, 1998).

[16] Yu. Yu. Tarasevich, Percolation. Theory. Application. Algorithms (Nauka. Moscow, 2002).

[17] K. Christensen, Percolation theory. (MIT Press, L., 2002).

[18] E.P. Mammun [et al.], Electroactive Polymeric Materials (Alpha Advertising, Kiev, 2013).

[19] A. Herega, J. of Materials Science and Engineering A 5(11-12), 409 (2015), https://doi.org/10.17265/21616213/2015.11-12.004.

[20] E.A. Lysenkov, Journal of Nano- and Electronic Physics 8(1), 01017 (2016), https://doi.org/10.21272/jnep.8(1).01017.

[21] A.G. Zabrodsky, S.A. Nemov, Yu.I. Ravich, Electronic Properties of Disordered Systems (St. Petersburg, Nauka, 2000).

[22] E.A. Lysenkov, YU.V. Yakovlev, V. V. Klepko, Polymer Journal. 35(3), 259 (2013), http://nbuv.gov.ua/UJRN/Polimer 2013 $35 \quad 3 \quad 9$.

[23] [A.L. Efros, B.I. Shklovskii, Phys. Status Solidi. 76(2), 475 (1976), https://doi.org/10.1002/pssb.2220760205.

[24] O. Yevchuk, O. Aksimentyeva, Yu. Horbenko, Visnyk Lviv University. Avg. chemical (53), 352 (2012).

[25] O. Aksimentyeva, V. Dutka, Yu.Gorbenko, G. Martyniuk, U. Riy, G. Zaslavska, Proceedings of the NTSh. Chem. science. XLVIII, 7 (2017). http://nbuv.gov.ua/UJRN/pntsh_him_2017_48_3.

[26] O. Aksimentyeva, G. Martyniuk, Proceedings of the NTSh. Chem. science LX, 14 (2020). https://doi.org/10.37827/ntsh.chem.

[27] V.I. Berezkin, V.V. Popov, Solid State Physics. 60(1), $292 \quad$ (2018), https://doi.org/10.21883/FTT.2018.01.45309.148

[28] A.V. Eletsky, A.A. Knizhnik, B.V. Potapkin, H.M. Kenny, UFN 185, 225 (2015), https://doi.org/10.3367/UFNr.0185.201503a.0225.

[29] I.M. Afanasov, V.A. Morozov, A.N. Seleznev, V.V. Avdeev, Inorganic materials 44(6), 598 (2008), https://doi.org/10.1134/s0020168508060101.

\section{О.І. Аксіментьєва ${ }^{1}$, Г.В. Мартинюк ${ }^{2}$}

\section{Перколяційні явища в полімерних композитах з електропровідними полімерними наповнювачами}

\footnotetext{
${ }^{1}$ Львівський національний університет імені Івана Франка вул. Кирила і Мефодія, 6/8, Львів 79005, aksimen@ukr.net ${ }^{2}$ Рівненський державний гуманітарний університет, вул. Пластова,31, в, Рівне, 33000, galmart@ukr.net
}

Вивчено електричні властивості полімерних нанокомпозитів на основі діелектричних полімерних матриць різного типу i електропровідних полімерних наповнювачів - поліортотолуїдину, поліортоанізидину та поліаніліну. Показано, що концентраційна залежність питомої електропровідності від вмісту наповнювачів має перколяційний характер з низьким „порогом перколяції”, який залежить від природи полімерної матриці та поліаміноарену і становить 1.7-10.0 об. \%. Розраховані критичні параметри електропровідності характерні для утворення нескінченного 3-х вимірного кластера провідності і свідчать про суттєвий вплив природи компонентів та морфології матеріалу на процеси перенесення заряду в таких системах.

Ключові слова: електричні властивості, перколяційні явища, поріг перколяції, полімерна матриця, електропровідний наповнювач. 